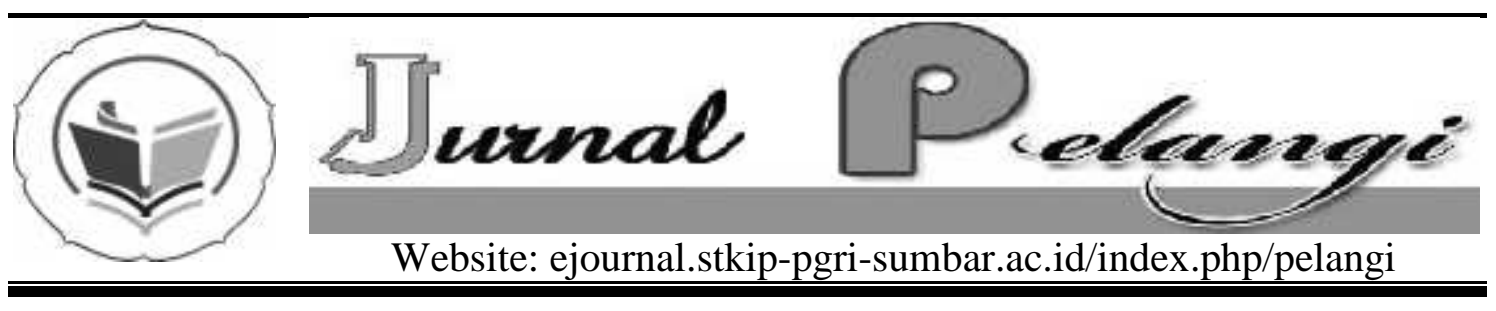

\title{
EFEKTIVITAS PENGEMBANGAN LEMBAR KERJA MAHASISWA PADA PERKULIAHAN BAHASA INGGRIS UNTUK MATEMATIKA
}

\author{
Anna Cesaria ${ }^{1)}$, Dewi Yuliana Fitri ${ }^{2)}$ \\ ${ }^{1,2)}$ Program Studi Pendidikan Matematika STKIP PGRI Sumatera Barat \\ 1) annacesaria13@gmail.com \\ ${ }^{2)}$ ewie_ssi@yahoo.co.id
}

INFO ARTIKEL

Diterima : 01/04/2014

Disetujui: 30/05/2014

\section{Kata Kunci:}

Efektivitas,

Lembar Kerja,

Bahasa Inggris

Matematika
Keywords:

Efectivity,

Jobsheet,

English for math

\begin{abstract}
Abstrak
Kemampuan berbahasa Inggris mahasiswa Pendidikan Matematika dapat dikembangkan melalui perkuliahan Bahasa Inggris untuk matematika. Agar kuliah maksimal diperlukan bahan ajar yang dapat mendukung proses perkuliahan. Mahasiswa hanya mengandalkan satu buku ketika kuliah, sehingga motivasi dan minat siswa dalam belajar menjadi rendah. Oleh karena itu, dibutuhkan bahan kuliah berupa LKM yang dapat membantu memfasilitasi siswa dalam kuliah. Tujuan penelitian ini adalah untuk mengembangkan LKM yang valid, praktis dan efektif dalam mata pelajaran Bahasa Inggris untuk Matematika di STKIP PGRI Sumatera Barat. Penelitian ini merupakan penelitian pengembangan. LKM ini dikembangkan dengan menggunakan model 4D (define, design, develop, dan disseminate). Pengumpulan data dilakukan dengan validasi dan ujicoba LKM. LKM divalidasi oleh dosen dan pakar Bahasa Inggris untuk Matematika, serta Dosen Bahasa Indonesia. Ujicoba dilakukan pada mahasiswa Pendidikan Matematika STKIP PGRI Sumbar untuk mengetahui kepraktisan dan efektivitas LKM. Hasil penelitian menunjukkan bahwa: LKM telah efektif. Hal ini terlihat dari aktivitas siswa dan motivasi yang tinggi untuk mengikuti perkuliahan.
\end{abstract}


the lecture, which is a LKM. The purpose of this study is to develop a LKM valid, practical and effective in subjects STKIP PGRI English for mathematics in West Sumatra. This study is a research development. This LKM was developed by using the 4D model (define, design, develop, and desseminate). Phase desseminate not done. The data was collected with the validation and testing of the LKM. LKM is validated by the lecturer and expert English for mathematics, as well as Indonesian lecturers. Tests carried out on mathematics education students STKIP PGRI West Sumatra to know practicality and effectiveness of the LKM. The results showed that: LKM have been effective. This is evident from the activities of students and high motivation to learn after the lecture.

\section{PENDAHULUAN}

Perkuliahan Matematika ber-fungsi untuk mengembangkan kemampuan mengkomunikasikan gagasan melalui model Matematika yang dapat berupa kalimat dan persamaan Matematika. Pembelajaran Matematika bertujuan untuk melatih cara berpikir dan bernalar dalam menarik kesimpulan, mengembang-kan aktivitas kreatif yang melibatkan imajinasi, intuisi, dan penemuan. Selain itu, juga tujuan pembelajaran Matematika adalah untuk mengembangkan kemampuan pemecahan masalah dan mengembangkan kemampuan menyampaikan informasi atau mengkomunikasikan gagasan.

Kemampuan berbahasa Inggris diperlukan dalam perkuliahan Matematika, hal ini disebabkan karena banyak buku teks yang dipakai pada proses perkuliahan yang menggunakan Bahasa Inggris. Oleh karena itu, diperlukan suatu mata kuliah yang memperkenalkan istilah-istilah matematika dalam Bahasa Inggris. Mata kuliah Bahasa Inggris untuk Matematika adalah salah satu mata kuliah wajib yang diambil oleh mahasiswa prodi pendidikan Matematika STKIP PGRI Sumatera Barat. Mata Kuliah ini termasuk Mata Kuliah Berkehidupan Bersama (MBB) dengan bobot 2 sks. Mata kuliah ini mempelajari dan menginvetarisir konsep-konsep dan istilah-istilah dalam bidang geometri, aljabar, aritmatika, statistika, dll.

Mengingat pentingnya peranan mata kuliah ini, diharapkan mahasiswa bersungguh-sungguh dalam mengikuti perkuliahan. Mahasiswa diharapkan aktif, termotivasi, serta mampu menguasai standar kompetensi dari mata kuliah ini. Tujuan dari mata kuliah ini adalah agar mahasiswa tidak kesulitan dalam memahami buku teks berbahasa Inggris yang digunakan pada mata kuliah lain, yang cenderung mengunakan buku teks berbahasa Inggris. Disamping itu, dengan dikuasainya istilah-istilah Matematika dalam Bahasa Inggris dapat membantu mahasiswa mengajar di kelas internasional yang sudah mulai digalakkan pemerintah. Untuk menciptakan perkuliahan yang menarik diperlukan bahan ajar yang menarik dan interaktif.

Pada kenyataannya bahan perkuliahan pada mata kuliah ini belum menarik dan masih terbatas. Berdasarkan pengalaman peneliti selama mengampu mata kuliah ini, bahan ajar pada mata kuliah ini masih terbatas, 
belum interaktif, dan sulit untuk dipahami mahasiswa. Proses perkuliahan masih monoton dan bersifat satu arah. Sumber belajar yang kurang membuat mahasiswa mengalami kesulitan dalam memahami materi perkuliahan, misalnya ketika memahami materi mahasiswa kurang mengerti.

Salah satu cara untuk mengatasi masalah tersebut adalah, dikembangkan suatu bahan perkuliahan yang menarik dan interaktif yang berupa Lembar Kerja Mahasiswa (LKM). Bahan perkuliahan yang interaktif adalah bahan perkuliahan yang mengunakan bahasa-bahasa yang luwes dan tidak kaku. LKM berisi panduan-panduan materi dengan gambar-gambar yang menarik yang dikemas sedemikian rupa. Hal ini diharapkan dapat menjadikan perkuliahan menjadi lebih interaktif, memiliki daya tarik, bermakna serta tidak menjadikan mata kuliah ini sebagai mata kuliah yang membosankan bagi mahasiswa.

Berdasarkan latar belakang yang dijelaskan di atas, peneliti tertarik untuk melakukan penelitian dengan judul Efektivitas Pengembangan LKM Pada Perkuliahan Bahasa Inggris untuk Matematika di STKIP PGRI Sumatera Barat.

\section{METODE PENELITIAN}

Jenis penelitian ini adalah penelitian dan pengembangan (Research and development $/ R \& D)$. Menurut Sugiyono (2008:407), "R\&D adalah metode pelitian yang digunakan untuk menghasilkan produk tertentu, dan menguji keefektifan produk tersebut". Produk yang dikembangkan dalam penelitian ini adalah keefektifan LKM Bahasa Inggris untuk Matematika.

Model pengembangan LKM Bahasa Inggris untuk Matematika dalam penelitian ini menggunakan model pengembangan 4-D (Four D). Model pengembangan 4-D merupakan model pengembangan perangkat pembelajaran. Model ini dikembangkan oleh S. Thagarajan, Dorothy S. Semmel, dan Melvyn I. Semmel. Model pengembangan 4D terdiri atas 4 tahap utama yaitu: (1) Define (Pembatasan), (2) Design (Perancangan), (3) Develop (Pengembangan) dan Disseminate (Penyebaran), atau diadaptasi menjadi model 4-P, yaitu Pendefinisian, Perancangan, Pengembangan, dan Penyebaran Penelitian ini akan dilakukan dalam tiga tahap, yaitu define, design dan develop. Tahap disseminate tidak dilakukan karena mengingat keterbatasan waktu dan biaya. Secara lengkap prosedur yang akan dilakukan adalah sebagai berikut.

1.

pendefinisian (define)

Tahap

Pada tahap ini dilakukan langkahlangkah sebagai berikut.

a. Melakukan

wawancara dengan teman sejawat, bertujuan untuk mengetahui masalah/hambatan yang dihadapi di lapangan sehubungan dengan perkuliahan Bahasa Inggris untuk Matematika. Masalah/hambatan bisa berasal dari mahasiswa maupun dosen yang mengajar.

b.

Menganalisis silabus

Bahasa Inggris untuk Matematika, untuk mengetahui kesesuaian materi dengan kompetensi yang diharapkan.

c.

Menganalisis bukubuku teks Bahasa Inggris untuk Matematika, untuk melihat kesesuaian isi buku dengan standar kompetensi dan kompetensi dasar yang harus dicapai mahasiswa. Bukubuku yang telah sesuai akan digunakan sebagai acuan penyusunan konsep dan contoh soal serta latihan soal pada LKM yang akan dikembangkan. 
d. Mereview literatur yang terkait dengan pengembangan LKM.

2. an (design)

Perancang

Pada tahap ini dilakukan langkahlangkah sebagai berikut.

a.

Merancang format

LKM Bahasa Inggris untuk Matematika. LKM ini akan terdiri dari 1 bab

b.

Bab berisi ringkasan pokok, contoh soal, latihan, evaluasi. Dalam setiap bab bisa terdiri atas beberapa kali pertemuan yang sudah disesuaikan dengan silabus.

3.

ngan (develop)

Pada tahap ini tindakan yang dilakukan adalah memvalidasi, menguji praktikalitas dan efektifitas LKM. Berhubung LKM nya sudah valid dan praktis maka dilakukan ujicoba untuk mengetahui efektivitas LKM. ujicoba ini dilakukan untuk menilai apakah LKM yang dikembangkan dapat digunakan sesuai harapan untuk meningkatkan kualitas dan prestasi belajar mahasiswa. Pada uji coba ini akan diamati motivasi, aktivitas, dan hasil belajar mahasiswa untuk mengetahui tingkat efektifitas
LKM yang telah dikembangkan. Adapun indikator efektivitas LKM dapat dilihat pada Tabel 1 .

Jika LKM belum efektif maka dilakukan revisi pada bagian yang masih dianggap kurang. Hasil revisi ini dijadikan tolak ukur dalam memperbaiki LKM yang telah dikembangkan. Maka hasil ini menjadi hasil akhir rangkaian pengembangan LKM.

Instrumen yang digunakan adalah lembar validasi, angket motivasi, dan tes. Lembar validasi angket motivasi belajar mahasiswa bertujuan untuk mengetahui apakah angket motivasi belajar mahasiswa yang telah dirancang valid atau tidak. Lembar validasi ini diisi oleh validator. Skala penilaian untuk lembar validasi menggunakan skala Likert.

Angket motivasi dikembangkan untuk melihat motivasi mahasiswa selama perkuliahan Bahasa Inggris untuk Matematika dengan menggunakan LKM. Angket ini terdiri dari 36 pernyataan-pernyataan dengan lima alternatif jawaban, yaitu sangat tidak setuju, tidak setuju, ragu-ragu, setuju dan sangat setuju. Angket terbagi atas 4 aspek yaitu minat, relevansi, manfaat dan kepuasan.

Tabel 1. Indikator Efektifitas LKM

\begin{tabular}{|c|c|c|}
\hline Aspek yang dinilai & Metode pengumpulan data & Instrumen \\
\hline Efektifitas : & \multirow{4}{*}{$\begin{array}{l}\text { a. Observasi } \\
\text { b. Angket motivasi } \\
\text { c. Hasil penilaian } \\
\text { pembelajaran }\end{array}$} & \multirow{4}{*}{$\begin{array}{l}\text { a. Lembar } \\
\text { observasi } \\
\text { b. Angket } \\
\text { c. Tes }\end{array}$} \\
\hline $\begin{array}{l}\text { a. Dampak terhadap } \\
\text { aktivitas belajar }\end{array}$ & & \\
\hline $\begin{array}{l}\text { b. Dampak terhadap } \\
\text { motivasi }\end{array}$ & & \\
\hline $\begin{array}{l}\text { c. Dampak terhadap hasil } \\
\text { belajar }\end{array}$ & & \\
\hline
\end{tabular}

Tabel 2. Kriteria Keberhasilan Efektif Mahasiswa

\begin{tabular}{lll}
\hline Nilai Mutu Nilai Angka & Keterangan \\
\hline
\end{tabular}




\begin{tabular}{lcc}
\hline A & $81<\mathrm{k} \leq 100$ & Baik sekali \\
B & $66<\mathrm{k} \leq 80$ & Baik \\
C & $56<\mathrm{k} \leq 65$ & Cukup \\
D & $46<\mathrm{k} \leq 55$ & Kurang Cukup \\
E & $\mathrm{k}<45$ & Kurang \\
\hline
\end{tabular}

Sumber: Buku Pedoman Akademik STKIP PGRI (2011/2012)

Tes digunakan untuk mengetahui hasil belajar mahasiswa setelah menggunakan LKM. Melalui tes tersebut dapat ditentukan tinggi rendahnya skor dalam bentuk kuantitatif selanjutnya dibandingkan dengan standar yang telah ditentukan untuk ditarik kesimpulan yang bersifat kualitatif.

Data efektifitas diperoleh dari lembar observasi dan angket. Data tersebut dianalisis secara kualitatif dan kuantitatif. Hasil yang diperoleh dari angket, lembar observasi efektifitas, dan lembar validasi dianalisis secara kuantitatif, selanjutnya hasil analisis kuantitatif tersebut akan ditarik suatu kesimpulan.

Data yang diperoleh dari tes hasil belajar dianalisis dengan menggunakan perhitungan persentase mahasiswa yang memenuhi kriteria ketuntasan minimal. Untuk pengembangan LKM ini dikatakan efektif jika lebih dari $70 \%$ mahasiswa mendapatkan nilai 65-100.

\section{HASIL DAN PEMBAHASAN}

Penelitian pengembangan ini menghasilkan produk berupa LKM. LKM ini memfasilitasi proses belajar mandiri bagi mahasiswa. Setelah LKM dinyatakan valid dan praktis, dilakukan uji efektifitas. Sesuai dengan apa yang dikemukakan oleh Richey dan Nelson (2001 dalam 2010: 34) bahwa suatu media yang dikembangkan baru bisa digunakan dalam pembelajaran terlebih dahulu harus melewati uji validitas, praktikalitas dan efektifitas.
Untuk menjawab pertanyaan "Bagaimanakah efektivitas dari LKM pada perkuliahan Bahasa Inggris untuk Matematia di STKIP PGRI Sumatera Barat?", maka telah dilakukan deskripsi dan analisis data tentang aktivitas dan hasil belajar mahasiswa. Berdasarkan hasil analisis data pengamatan aktivitas mahasiswa selama perkuliahan menunjukkan bahwa perkuliahan dengan menggunakan LKM telah mendorong meningkatnya aktivitas belajar mahasiswa. Aspek efektivitas dapat dinilai apabila produk tersebut sudah valid dan praktis.

Berdasarkan hasil observasi aktivitas mahasiswa selama perkuliahan menunjukkan bahwa LKM pada perkuliahan Bahasa Inggris untuk Matematika dapat memunculkan aktivitas positif dan mengurangi aktivitas negatif mahasiswa.

Aktivitas yang banyak sekali muncul dan sangat berhasil dilaksanakan di kelas adalah visual activities (membaca LKM) dan writing activities (mengerjakan latihan). Membaca LKM akan membantu mahasiswa dalam memahami materi dan mengerjakan latihan dapat menguji sejauh mana pemahaman mahasiswa terhadap materi yang telah dibaca tersebut.

Aktivitas lainnya yang banyak muncul dan berhasil dilaksanakan adalah drawing activities (menggambar atau membuat sketsa) dan mental activities (menanggapi, menganalisis, melihat hubungan dan menyimpulkan pembelajaran). Mahasiswa membuat gambar atau sketsa grafik ketika 
melakukan penemuan konsep dan menyelesaikan latihan.

Hasil belajar mahasiswa yang diperoleh melalui tes menunjukkan bahwa lebih dari $70 \%$ mahasiswa memperoleh nilai yang berkisar antara 65-100. Ini berarti pengembangan modul pada perkuliahan Bahasa Inggris untuk Matematika dapat dikatakan efektif.

\section{UCAPAN TERIMA KASIH}

Terbitnya tulisan ini tidak terlepas dari bantuan berbagai pihak, untuk itu penulis ucapkan terima kasih yang sebesar-basarnya kepada Pihak STKIP PGRI Sumatera Barat khususnya pengelola jurnal Pelangi yang telah memberikan kesempatan kepada penulis untuk menulis dijurnal Pelangi.Selanjutnya penulis juga berterima kasih kepada para penyumbang sumber insirasi yang telah memerikan inspirasi bagi penulis untuk mengutip atau menggunakan tulisannya sebagai bahan referensi.

\section{DAFTAR RUJUKAN}

Anas Sudijono. 2005. Pengantar Statistik Pendidikan. Jakarta: RajaGrafindo Persada.

Brown, Michael J. 2008. Kamus Matematika Remaja. Grasindo. Jakarta.

Dimyati dan Mudjiono. 2006. Belajar dan Pembelajaran. Jakarta: PT. Rineka Cipta.

Djaali dan Pudji Muljiono. 2008. Pengukuran dalam Bidang Pendidikan.Jakarta: PT Grasindo.

Depdiknas. 2006. Pengembangan Bahan Ajar. www.jardiknas.org

Encyclopedia of Mathematics. Van Nostrand.

Nurmaiyenti, $\quad$ Isra. 2008. "Pengembangan Buku Kerja Berbasis Konstruktivisme Pada
Perkuliahan Kalkulus 1 Di Stain Batusangkar". Tesis tidak diterbitkan. Padang: Program Pasca Sarjana UNP.

Kerami, Djati, dkk. 1995. Glosarium Matematika. Balai Pustaka. Jakarta.

Kerami, Djati, dkk. 2003. Kamus Matematika. Balai Pustaka. Jakarta.

Markaban. 2006. Model Pembelajaran Matematika dengan Pendekatan Penemuan

Terbimbing. Yogyakarta:

Departemen Pendidikan Nasional.

Markaban. 2008. Model Penemuan Terbimbing Pada Pembelajaran Matematika SMK. Yogyakarta: Departemen Pendidikan Nasional.

Muliyardi. 2006. Pengembangan Model Pembelajaran Matematika dengan Mengguna-kan Komik di Kelas 1 Sekolah Dasar. Disertasi tidak diterbitkan. Surabaya: Pasca Sarjana UNESA.

Oemar Hamalik. 2004. Psikologi Belajar dan Mengajar. Bandung: Sinar Baru Algesindo.

Riduwan. 2005. Belajar Mudah Penelitian untuk Guru, Karyawan dan Peneliti Pemula. Bandung: Alfabeta.

Roza, Yenita. 2006. English for Basic Mathematics. FKIP UNRI.

Sadirman. 2011. Interaksi dan Motivasi Belajar Mengajar. Jakarta: PT Raja Grafindo Persada.

Sugiyono. 2008. Metode Penelitian Pendidikan. Bandung: CV. Alfabeta.

Suprawoto. 2009. Mengembnagkan Bahan Ajar dengan Menyusun Modul.

(http://www.scribd.com/doc/16554 502/Mengembangkan-Bahan-Ajar dengan-Menyusun-Modul, diakses 10 April 2010). 
Suryobroto. 1983. Sistem Pengajaran dengan Modul. Yogyakarta: PT. Bina Aksara.

Soon, Yong Kwee.2007. Total pro Mathematics. Petaling jaya: Sasbadi Sdn. Bhd.

Tarigan, Elieser \& Fitri Dwi K. 2011. Cara Brilliant Pengucapan matematika dalam Bahasa Inggris. Brilian Internasional Surabaya.

Tim Redaksi Kamus Besar Bahasa Indonesia. 2002. Kamus Besar bahasa Indonesia Edisi Ketiga. Balai Pustaka: Jakarta.

Trianto. 2009. Mendesain Model Pembelajaran Inovatif-Progresif: Konsep, Landasan, dan
Implementasinya pada Kurikulum Tingkat Satuan Pendidikan (KTSP). Jakarta: Kencana.

Yasmin, Nyimas. 2007. Pengembangan Perangkat Pembelajaran Berbasis RME untuk Kelas IV Sekolah Dasar. Tesis tidak diterbitkan. Padang: Pasca Sarjana UNP.

Yusri, Amdal. 2008. "Pengaruh Metode Penemuan Terbimbing Terhadap Hasil Belajar Matematika Pada Pokok Bahasan Bangun Ruang Sisi Lengkung Siswa Kelas IX di MTSN I Bukittinggi TP. 2007/2008". Tesis tidak diterbitkan. Padang: Program Pasca Sarjana UNP. 